\title{
Investigation on the Delamination of Ni-P/ Glass fiber / Nanowire -Reinforced Vinyl Ester Composite
}

\author{
Anand G, Alagumurthi N, Elansezhain R \\ Department of Mechanical Engineering \\ Pondicherry Engineering College, \\ Puducherry, India
}

\author{
Venkateshwaran R \\ Department of Mechanical Engineering \\ Rajalakshmi Engineering College, \\ Thandalam, Chennai, India
}

\begin{abstract}
Glass fiber reinforced hybrid plastic composites are used as an alternative material for many conventionally used engineering materials because of their high strength properties. The drilling has become one of the necessary processes involved during the manufacturing of large structures. In the current study, the delamination effect on the Ni-P - GF / Al2O3 nanowire reinforced hybrid composites are analyzed at both the ends of the machined holes. Taguchi's L25, 5-level orthogonal array with Grey relational analysis is employed for optimizing the drilling parameters such as spindle speed, feed rate and diameter. Grey relational grade analysis is used for optimizing the multiple output responses and from the study, it is clear that the most influencing parameter is the drill diameter followed by feed rate and spindle speed. The optimum machining parameters are identified for drilling the newly developed hybrid vinyl ester composites.
\end{abstract}

Keywords - Drilling; Delamination; Hybrid composite; Optimization; Grey relational analysis.

\section{INTRODUCTION}

Hybrid composites (GFRP) are widely used in many engineering applications such as automotive, aerospace, marine, and sporting goods because of their properties such as high strength to weight ratio, good resistance to wear and corrosion, light weight, etc [1]. The machining of composite materials is very tedious. However, the use of high speed steel (HSS) twist drill bit was found to be the efficient during drilling of polymer composite materials. The drilling process was used for making holes, riveting and fastening the structures in marine, automotive and aerospace applications [2]. Along with the drilling of polymeric composite materials, many problems associates such as fiber pullout, delamination, fuzziness, thermal degradation, mechanical cracks, etc. This was because of the anisotropic property of the composite materials. The machining of these anisotropic composites materials requires the better understanding of both the materials and the drilling process to achieve a best result [3]. The process of drilling hybrid composite differs in that of convention materials. Some kinds of problems are associated in materials, such as rough drilled surface, fiber/matrix debonding, and delamination during the machining process, etc. The delamination arises during the drilling process has to be maintained at minimum possible level. Many researchers have investigated the drilling of fiber reinforced composite materials. Khashaba et al [4] studied the influences of the drilling parameters on the delamination of GFRP by a simpler technique to measure it. Mohan et al [5] observed the effect of cutting parameter on the delamination in drilling GFRP composite. In the aircraft industries, the rejection of parts due to the delamination damages during final assembly was as high as $60 \%$. Latha [6] et al found that the delamination on drilling GFRP composites and has developed a model using the fuzzy rule-based model for predicting delamination in drilling of GFRP. Taguchi is one of the most important methods that include the experimental plan with the objective of getting response data in a controlled way to analysis [7]. Davim et al [8] utilized Taguchi and analysis of variance (ANOVA) methods to study the effect of cutting speed and feed in thrust force and damage and surface roughness induced in glass fiber reinforced polymeric composite manufactured by hand lay-up technique and found that the speed has the maximum effect on the response rather than other. Palanikumar et al. [9] have conducted the experiments by using HSS twist drill and have used regression and ANOVA for analysis. Multiple responses can be optimized by many methods, one such popularly used method was Grey relational technique. Palanikumar et al [10] have optimized the machining parameter such as spindle speed, feed rate and drill diameter for the response such as thrust force and surface roughness by grey relational grade method. For the practical machining of GFRP composite materials, it was necessary to determine the optimal machining parameter to achieve better performance such as less delamination, good surface finish, etc. The multiple response optimizations are more complex when compared to the optimization of single response characteristic. The grey relational technique is a method used for analyzing the relationship between sequences, using fewer data and multifactor [11]. This is viewed as one of the most advantageous statistical regression analysis technique. The grey relation analysis was successfully applied in the manufacturing process. Tosun [12] have used grey relation analysis for optimizing the drilling parameters. Yiyo Kuo et al. [13] have applied Taguchi method and Grey relational technique for optimizing the multi-response characteristic in the problem. The present work focuses on the use of grey relational analysis for optimizing the drilling parameters for the delamination at the inlet and the exit.

\section{EXPERIMENTAL WORK}

The work piece used for the current investigation was hybrid polymer composite reinforced with nickel phosphorus coated glass fiber (Ni-P/GF) and Aluminium oxide $\left(\mathrm{Al}_{2} \mathrm{O}_{3}\right)$ nanowires. The matrix material is the vinyl ester since it has higher mechanical and thermal properties than polyester and it is used in many structural, marine, aerospace and industrial 
applications. The Ni-P coated glass fiber and nanowires concentration in the samples are invariably upheld at $45 \mathrm{wt}$. $\%$ and $0.75 \%$ respectively.

TABLE 1. EXPERIMENTAL PARAMETERS AND THEIR LEVELS

\begin{tabular}{|c|c|c|c|c|c|}
\hline $\begin{array}{c}\text { Cutting } \\
\text { Parameters }\end{array}$ & \multicolumn{7}{|c|}{ Levels } \\
\hline & Lowest & Lower & Medium & Higher & Highest \\
\hline $\begin{array}{c}\text { Spindle Speed } \\
\text { (RPM }\end{array}$ & 450 & 852 & 1260 & 1850 & 2700 \\
\hline $\begin{array}{c}\text { Feed Rate } \\
\text { (mm/min) }\end{array}$ & 30 & 40 & 50 & 60 & 70 \\
\hline $\begin{array}{c}\text { Drill Diameter } \\
(\mathrm{mm})\end{array}$ & 4 & 6 & 8 & 10 & 12 \\
\hline
\end{tabular}

The different trials of the drilling experiments are designed by Taguchi's orthogonal array. Taguchi method is used to reduce the number of trials required for the complete analysis [14-15]. The important factors which affect the machining process are spindle speed, feed rate, and drill diameter. The drilling parameter and levels are stated clearly in table 1. For carrying out the trials, the L25 orthogonal array had been preferred. The drilling trials are performed on Conventional Vertical Machining Centre coupled with a Kistler dynamometer. The delamination is measured by means of the computer assisted machine vision system. The effect of different machining parameters on drilling hybrid Ni-P/GFRP composite is studied by conducting tests using HSS twist drill bit of various diameters. The figure 1 shows the schematic drill bit used for drilling.

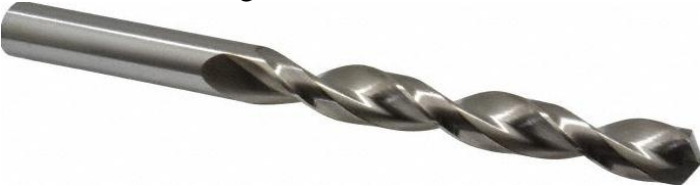

Figure 1. High speed drill bit used (12mm)

In drilling of GFRP composites, many factors affect the hole quality in which the delamination is the most important responses that determines the quality of the drilled hole. The delamination occurs both at the inlet and exit of the holes drilled and in both the response behave differently. The delamination has been measured by using machine vision system with diffused backlight technique assisted with 8 megapixel camera (make: opto engineering). The schematic experimental setup used for the present investigation is presented in Fig. 2. The experimental layout using Taguchi's orthogonal array is presented in Table 2.

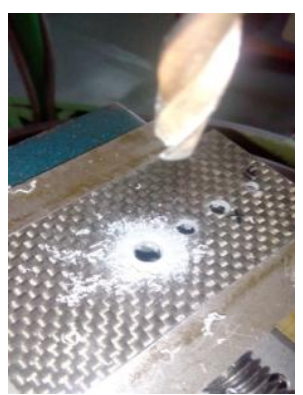

(a) Drilling Operation

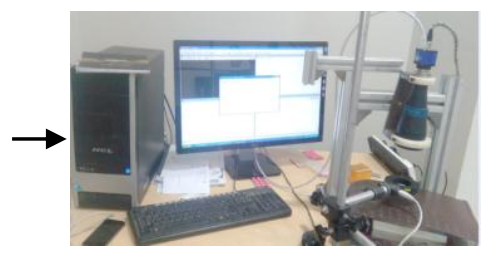

(b) Delamination measurement
Figure 2. The experimental setup

\section{A. Grey Relational Analysis}

The Grey relation analysis theory is an effective tool used for multiple response optimizations [12]. The Grey relational analysis is a measure of difference between the absolute value of the data and the sequences. It is also used to measure the close correlation among sequences [16]. In this present work, the Taguchi orthogonal array with the Grey grade is used to investigate the multiple response characteristics in the optimization of the drilling parameters.

The steps used for the optimization process are [16, 18]:

1. The observed results are normalized or pre-processed.

2. Deviation sequences are to be determined form the normalized data.

2. Grey relational coefficient is to be determined from the deviation sequenced data.

3. The average of the grey relational coefficient is called as the Grey relational grade.

4. Analyze the results by Grey relational grade and statistical analysis of variance.

5. Determine the optimum process parameter level.

\section{B. Data Pre-processing}

In Grey relational analysis, the experimental data of the inlet delamination and the exit delamination are to be preprocessing to transfer the original sequence of data to the comparable between zero and one. If the target value of the original sequence is infinite, then it has a characteristic of the "larger -the better." The original data can be normalized as follows:

$$
x_{i}^{*}(k)=\frac{x_{i}^{0}(k)-\min x_{i}^{0}(k)}{\max x_{i}^{0}(k)-\min x_{i}^{0}(k)}
$$

For "lower-the better" characteristic of the original sequence considered, the original sequence should be normalized as follows:

$$
x_{i}^{*}(k)=\frac{\max x_{i}^{0}(k)-x_{i}^{0}(k)}{\max x_{i}^{0}(k)-\min x_{i}^{0}(k)}
$$

However, if a definite target value (desired value) is to be determined, the original sequence will be normalized as follows:

$$
x_{i}^{*}(k)=1-\frac{\left\|x_{i}^{0}(k)-x^{0}\right\|}{\max x_{i}^{0}(k)-x^{0}}
$$

Or the original sequence can be simply normalized by the mast basic methodology, that is the value of original sequence be divided by the first value of the sequence

$$
x_{i}^{*}(k)=\frac{x_{i}^{0}(k)}{x_{i}^{0}(1)}
$$

Where $x_{i}^{0}(k)$ denotes the original sequence, $x_{i}^{*}(k)$ is the sequence after the data-pre-processing, $\max x_{i}^{*}(k)$ is the 
largest value of $x_{i}^{0}(k), \min x_{i}^{*}(k)$ is the smallest value of $x_{i}^{0}(k)$, and $\mathrm{x}^{0}$ is the desired value.

\section{Grey Relational Coefficient and Grey Relational Grade}

The relevancies between two systems are measured by Grey relational analysis. The sequences used in the Grey relational analysis are called Grey relational coefficient. The Grey relational coefficient $\xi(\mathrm{k})$ can be calculated as follows:

$\xi(\mathrm{k})=\frac{\Delta_{\min }+\xi \Delta_{\max }}{\Delta 0 \mathrm{i}(\mathrm{k})+\xi \Delta \max }$

where $\Delta_{0 \mathrm{i}}$ denotes the absolute value of the difference between $x_{i}^{0}(k)$ and $x_{i}^{*}(k)$, and it is also known as the deviation sequence. $\xi$ is the distinguishing coefficient. If the value of the $\xi$ is smaller, then the distinguished ability is larger. In general, $\xi=0.5$ is used:

$$
\Delta_{0 \mathrm{i}}=\left\|x_{0}^{*}(k)-x_{i}^{0}(k)\right\|
$$

(6)

$$
\begin{aligned}
& \Delta_{\min }=\left(\min _{\forall j \in i}\right)\left(\min _{\forall k}\right) \| x_{0}^{*}(k)-x_{j}^{*}(k) \\
& \Delta_{\max }=\left(\max _{\forall j \in i}\right)\left(\max _{\forall k}^{\max }\right)\left\|x_{0}^{*}(k)-x_{j}^{*}(k)\right\|
\end{aligned}
$$

After the Grey relational coefficient is derived, the average value of the Grey relational coefficient is taken as the Grey relational grade [12]. The Grey relational grade is defined as follows:

$$
\gamma_{\mathrm{i}}=\frac{1}{n} \sum_{k=1}^{n} \xi_{i}(k)
$$

However, in a real engineering system, the importance of various factors in the system varies according to the real condition of an unequal weight are carried for different factors. The Grey relational grade in Eq. (9) is extended and defined as $[12,16]$

$$
\gamma_{i}=\frac{1}{n} \sum_{k=1}^{n} \quad w_{k} \xi_{i}(k)_{3}
$$

Where, $w_{k}$ denotes the normalized weight of factor $k$. If $w_{k}$ is same for all factors then, Eqs. (9) \& (10) are equal. The Grey

\begin{tabular}{|c|c|c|c|}
\hline Experiment No. & $\begin{array}{l}\text { Spindle } \\
\text { speed } \\
\text { (RPM) }\end{array}$ & $\begin{array}{l}\text { Feed rate } \\
(\mathrm{mm} / \mathrm{min})\end{array}$ & $\begin{array}{l}\text { Drill Diameter } \\
(\mathrm{mm})\end{array}$ \\
\hline 1 & 450 & 30 & 4 \\
\hline 2 & 450 & 40 & 6 \\
\hline 3 & 450 & 50 & 8 \\
\hline 4 & 450 & 60 & 10 \\
\hline 5 & 450 & 70 & 12 \\
\hline 6 & 852 & 30 & 6 \\
\hline 7 & 852 & 40 & 8 \\
\hline 8 & 852 & 50 & 10 \\
\hline 9 & 852 & 60 & 12 \\
\hline 10 & 852 & 70 & 4 \\
\hline 11 & 1260 & 30 & 8 \\
\hline 12 & 1260 & 40 & 10 \\
\hline 13 & 1260 & 50 & 12 \\
\hline 14 & 1260 & 60 & 4 \\
\hline 15 & 1260 & 70 & 6 \\
\hline 16 & 1860 & 30 & 10 \\
\hline 17 & 1860 & 40 & 12 \\
\hline 18 & 1860 & 50 & 4 \\
\hline 19 & 1860 & 60 & 6 \\
\hline 20 & 1860 & 70 & 8 \\
\hline 21 & 2700 & 30 & 12 \\
\hline 22 & 2700 & 40 & 4 \\
\hline 23 & 2700 & 50 & 6 \\
\hline 24 & 2700 & 60 & 8 \\
\hline
\end{tabular}
relational grade shows the degree of influence by the comparability sequence over the reference sequence [17].
TABLE 2 EXPERIMENTAL DESIGN USING TAGUCHI ORTHOGONAL ARRAY

\section{RESULTS AND DISCUSSION}

The result analysis suggests that the mechanics of drilling hybrid composites was not same as that of conventional materials due to the combination of plastic deformation, shearing, and flexural rupture. The happening of the above stated mechanisms mainly depend on the flexibility, orientation, and toughness of the fibers [19] and nanoparticles. Normally, the delamination phenomenon at the entry and exit was highly influenced by the drill diameter and feed rate. From the experiment results, it is found that the delamination increases with respect to the increase in the feed rate and drill diameter for both at the inlet and exit. At the lowest feed rate, good quality drilled holes are noticed. During the drilling operation, due to the push-out action at the exit of the drilled holes the fiber in the periphery peels. 

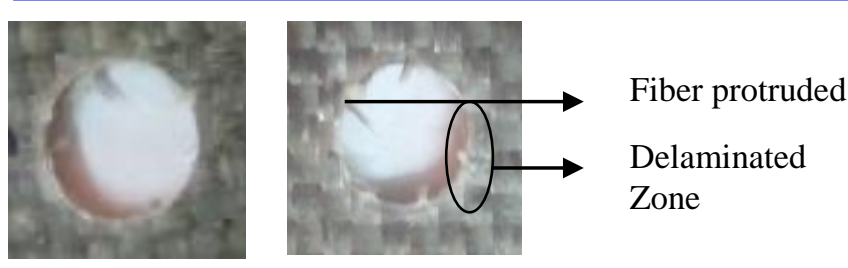

Figure 3. Delamination at the inlet and exit

Figure 3 clearly shows the image of drilled holes at the inlet and exit side of the hybrid composite laminate at spindle speed of the $1260 \mathrm{rpm}$ and with respect to $12 \mathrm{~mm}$ drill diameter and $50 \mathrm{~mm} / \mathrm{min}$ feed rate. It also indicates the protruding fibers in the drilled holes. The fiber protruding takes place because before the exit of the drill bit, it forces last layer of the material to be removed by push out action and thus the fiber is improperly cut and appeared frayed. At high speed and low feed rate and drill diameter, the fiber protruding and delamination are reduced. During drilling, the force in the axial direction of the slope of drill results in separation of the laminas from each other and hence delamination is raised [10].

Grey relational analysis is employed in the present work. Taguchi's L25 orthogonal array was used for generating data and is shown in Table 2. For both the delamination at inlet and exit, "lower-the-better" characteristic was considered. Table 3 shows the response characteristics of the delamination at the inlet and exit after data preprocessing.

After the data preprocessing, the deviation sequence $\Delta 0 \mathrm{i}$, $\Delta \max (\mathrm{k})$, and $\Delta \min (\mathrm{k})$ for $\mathrm{i}=1-25, \mathrm{k}=1-2$ can be determined. For example, the deviation sequence of the delamination for the experiment number 1 is as follows:

$\Delta 01(1)=|-|=|1.000-0.833|=0.167$.

The deviation sequence determined after the normalizing is shown in Table 4. Using Table 4, the values for $\Delta \max$ and $\Delta \min$ is found as 1 and 0 respectively.
The distinguishing coefficient $\xi$ is used in the formula to determine the Grey relational coefficient. If the distinguishing coefficient value $\xi$ is smaller, its ability will be large. Generally, the value of $\xi$ used is 0.5 . The value of Grey relational coefficient and the Grey relational grade for each experiment are shown in Table 5. Using the Grey relational grade, the Grey relational graph is drawn and presented in Fig. 4. From figure 4 and table 5 , it is observed that the experiment number 22 has the highest Grey relational grade. Therefore, the machining parameters for the experiment number 22, is the said to be optimum for attaining multiple performance among the 25 experiments.

\section{TABLE 3. THE SEQUENCE OF PERFORMANCE CHARACTERISTICS AFTER NORMALIZING / DATA PREPROCESSING}

\begin{tabular}{|c|c|c|}
\hline Experiment No. & Delamination Inlet & Delamination Exit \\
\hline 1 & 0.833 & 1 \\
\hline 2 & 0.667 & 0.810 \\
\hline 3 & 0.458 & 0.619 \\
\hline 4 & 0.208 & 0.429 \\
\hline 5 & 0 & 0.238 \\
\hline 6 & 0.833 & 0.762 \\
\hline 7 & 0.625 & 0.571 \\
\hline 8 & 0.375 & 0.333 \\
\hline 9 & 0.167 & 0.048 \\
\hline 10 & 0.583 & 0.429 \\
\hline 11 & 0.875 & 0.619 \\
\hline 12 & 0.625 & 0.429 \\
\hline 13 & 0.458 & 0.143 \\
\hline 14 & 0.708 & 0.476 \\
\hline 15 & 0.458 & 0.190 \\
\hline 16 & 0.708 & 0.571 \\
\hline 17 & 0.542 & 0.238 \\
\hline 18 & 0.833 & 0.571 \\
\hline 19 & 0.5 & 0.286 \\
\hline 20 & 0.333 & 0.095 \\
\hline 21 & 0.708 & 0.524 \\
\hline 22 & 1 & 0.857 \\
\hline 23 & 0.75 & 0.476 \\
\hline 24 & 0.542 & 0.190 \\
\hline 25 & 0.333 & 0 \\
\hline
\end{tabular}




\begin{tabular}{|c|c|c|}
\hline Experiment No. & Delamination Inlet & Delamination Exit \\
\hline 1 & 0.167 & 0 \\
\hline 2 & 0.333 & 0.190 \\
\hline 3 & 0.542 & 0.381 \\
\hline 4 & 0.791 & 0.571 \\
\hline 5 & 1 & 0.762 \\
\hline 6 & 0.167 & 0.238 \\
\hline 7 & 0.375 & 0.429 \\
\hline 8 & 0.625 & 0.667 \\
\hline 9 & 0.833 & 0.952 \\
\hline 10 & 0.417 & 0.571 \\
\hline 11 & 0.125 & 0.381 \\
\hline 12 & 0.375 & 0.571 \\
\hline 13 & 0.542 & 0.857 \\
\hline 14 & 0.292 & 0.524 \\
\hline 15 & 0.542 & 0.810 \\
\hline 16 & 0.292 & 0.429 \\
\hline 17 & 0.458 & 0.762 \\
\hline 18 & 0.167 & 0.429 \\
\hline 19 & 0.5 & 0.714 \\
\hline 20 & 0.667 & 0.905 \\
\hline 21 & 0.292 & 0.476 \\
\hline 22 & 0 & 0.143 \\
\hline 23 & 0.25 & 0.524 \\
\hline 24 & 0.458 & 0.810 \\
\hline 25 & 0.667 & 1 \\
\hline
\end{tabular}

TABLE 5. THE CALCULATED GREY RELATIONAL COEFFICIENT AND GREY RELATIONAL GRADE

\begin{tabular}{|c|c|c|c|c|}
\hline \multirow{2}{*}{$\begin{array}{l}\text { Experiment } \\
\text { No. }\end{array}$} & \multicolumn{2}{|c|}{$\begin{array}{c}\text { Grey Relational } \\
\text { Coefficient }\end{array}$} & \multirow{2}{*}{$\begin{array}{c}\text { Grey } \\
\text { relation } \\
\text { al } \\
\text { Grade }\end{array}$} & \multirow{2}{*}{$\begin{array}{l}\text { Rank / } \\
\text { Order }\end{array}$} \\
\hline & $\begin{array}{l}\text { Delaminat } \\
\text { ion Inlet }\end{array}$ & $\begin{array}{l}\text { Delaminati } \\
\text { on Exit }\end{array}$ & & \\
\hline 1 & 0.750 & 0.896 & 0.823 & 03 \\
\hline 2 & 0.600 & 0.579 & 0.589 & 10 \\
\hline 3 & 0.480 & 0.428 & 0.454 & 18 \\
\hline 4 & 0.387 & 0.355 & 0.371 & 23 \\
\hline 5 & 0.333 & 0.333 & 0.333 & 25 \\
\hline 6 & 0.750 & 0.887 & 0.819 & 04 \\
\hline 7 & 0.571 & 0.607 & 0.588 & 11 \\
\hline 8 & 0.444 & 0.428 & 0.436 & 20 \\
\hline 9 & 0.375 & 0.356 & 0.366 & 24 \\
\hline 10 & 0.545 & 0.621 & 0.584 & 12 \\
\hline 11 & 0.800 & 0.773 & 0.787 & 05 \\
\hline 12 & 0.571 & 0.445 & 0.508 & 15 \\
\hline 13 & 0.480 & 0.355 & 0.418 & 22 \\
\hline 14 & 0.632 & 0.600 & 0.616 & 08 \\
\hline 15 & 0.480 & 0.728 & 0.604 & 09 \\
\hline 16 & 0.632 & 0.438 & 0.535 & 13 \\
\hline 17 & 0.522 & 0.383 & 0.453 & 19 \\
\hline 18 & 0.750 & 1.000 & 0.875 & 02 \\
\hline 19 & 0.500 & 0.766 & 0.633 & 07 \\
\hline 20 & 0.429 & 0.502 & 0.465 & 17 \\
\hline 21 & 0.632 & 0.357 & 0.494 & 16 \\
\hline 22 & 1.000 & 0.907 & 0.953 & 01 \\
\hline 23 & 0.667 & 0.603 & 0.635 & 06 \\
\hline 24 & 0.522 & 0.516 & 0.519 & 14 \\
\hline 25 & 0.429 & 0.427 & 0.428 & 21 \\
\hline
\end{tabular}

However, the importance's of the different drilling parameters for the multiple performance characteristics are to be analyzed, to determine the optimal combination for drilling parameters. For analyzing the outcome, average grey relational grade by factor level is presented as response table in Table 6.

TABLE 6. THE RESPONSE TABLE FOR GREY RELATIONAL GRADE

\begin{tabular}{cccc}
\hline \multirow{2}{*}{$\begin{array}{c}\text { Machining } \\
\text { Parameters }\end{array}$} & \multicolumn{3}{c}{ Average Grey relational grade by factor level } \\
\cline { 2 - 4 } & $\begin{array}{c}\text { Spindle Speed, } \\
\text { RPM }\end{array}$ & $\begin{array}{c}\text { Feed Rate, } \\
\mathrm{mm} / \mathrm{min}\end{array}$ & $\begin{array}{c}\text { Drill } \\
\text { Diameter, mm }\end{array}$ \\
\hline Level 1 & 0.5143 & 0.6915 & 0.7701 \\
Level 2 & 0.5587 & 0.6185 & 0.6560 \\
Level 3 & 0.5864 & 0.5636 & 0.5628 \\
Level 4 & 0.5921 & 0.5008 & 0.4557 \\
Level 5 & 0.6058 & 0.4828 & 0.4127 \\
\hline Delta & 0.0915 & 0.2087 & 0.3574 \\
Rank & 3 & 2 & 1 \\
\hline
\end{tabular}


In this analysis, a larger value of Grey relational grade gives the better performance [12], and therefore the parameters corresponding to it gives the optimal level for drilling with minimum delamination at both ends. Based on the Grey relational analysis, from figure 5, the optimum parameters in the current investigation are observed at level 5 for spindle speed, level 1 for the feed rate and level 1 for the drill diameter. However, the relative importance's of the drilling parameters for multiple characteristics are to be analyzed by statistical analysis of variance. Its purpose was to analyze the drilling parameter that significantly affects the process. This was carried out by dividing the total variability of Grey relational grades, which was measured by the sum of squared deviations from the total mean of it into contributions by each machining parameter. The fisher's F-test value was used to determine the significance of the machining parameter on its performance characteristic. When the value of $\mathrm{F}$ was large, it means that it has the maximum effect on the response output. Based on the results of analysis of variance (Table 7), it was clear that the drill diameter has a maximum influences on the multiple performance characteristic during drilling in the hybrid composite.

The outcome of different parameters on the delamination at entry and exit (represented by Grey relational grade) can be clearly studied by the three-dimensional surface graphs. Figure 6(a) shows the effect of drilling parameters such as the drill diameter and the feed rate in the drilling of GFRP composites. From the figure 6(a), it can be inferred that the increase in the feed rate decreases the delamination at the inlet and exit while drilling hybrid GFRP composites. The maximum Grey relational grade represents the best machining parameter in drilling. Figure 6(b) shows the outcome of drilling parameters such as the drill diameter and spindle speed on Grey relational grade (GRG). Figure 6(b) also points that the increase of the spindle speed slightly decreases delamination at both the ends, whereas the increase in drill diameter increases the total delamination in the drilling of hybrid GFRP composite. Figure 6(c) shows the effect of spindle speed and feed rate with respect to grey relational grade. From the outcome, it is observed that the high spindle speed, the low feed rate, and minimum drill diameter are preferable for drilling hybrid GFRP composite.

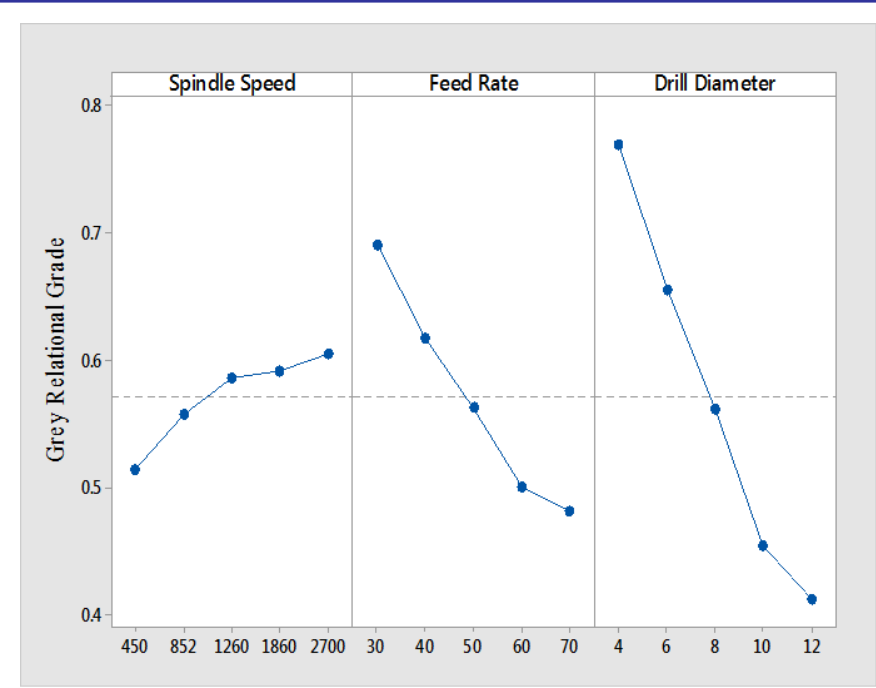

Figure 5. Effect of drilling parameters level on the multiple performance

TABLE 7. RESULT OF ANOVA

\begin{tabular}{|c|c|c|c|c|c|}
\hline Source & DF & $\begin{array}{l}\text { Sum } \\
\text { Square }\end{array}$ & $\begin{array}{l}\text { Mean } \\
\text { Square }\end{array}$ & $\begin{array}{l}\text { F- } \\
\text { Value }\end{array}$ & $\begin{array}{l}\% \\
\text { Contribu } \\
\text { tion }\end{array}$ \\
\hline Regression & 7 & 0.6102 & 0.0872 & 22.80 & 90.38 \\
\hline $\begin{array}{l}\text { Spindle } \\
\text { Speed, RPM }\end{array}$ & 1 & 0.0265 & 0.0266 & 6.96 & 3.05 \\
\hline $\begin{array}{l}\text { Feed Rate, } \\
\mathrm{mm} / \mathrm{min}\end{array}$ & 1 & 0.1369 & 0.1369 & 35.82 & 21.21 \\
\hline $\begin{array}{l}\text { Drill } \\
\text { Diameter, mm } \\
\text { Spindle }\end{array}$ & 1 & 0.3309 & 0.3309 & 86.55 & 62.01 \\
\hline $\begin{array}{l}\text { Speed*Feed } \\
\text { Rate } \\
\text { Spindle }\end{array}$ & 1 & 0.0029 & 0.0029 & 0.75 & 0.07 \\
\hline $\begin{array}{l}\text { Speed*Drill } \\
\text { Diameter } \\
\text { Feed }\end{array}$ & 1 & 0.0003 & 0.0003 & 0.09 & 2.68 \\
\hline $\begin{array}{l}\text { Rate*Drill } \\
\text { Diameter } \\
\text { Spindle }\end{array}$ & 1 & 0.0080 & 0.0080 & 2.10 & 1.18 \\
\hline $\begin{array}{l}\text { Speed*Feed } \\
\text { Rate*Drill } \\
\text { Diameter }\end{array}$ & 1 & 0.0012 & 0.0012 & 0.32 & 0.18 \\
\hline Error & 1 & 0.0648 & 0.0038 & & 9.62 \\
\hline Total & & & & & 100 \\
\hline
\end{tabular}

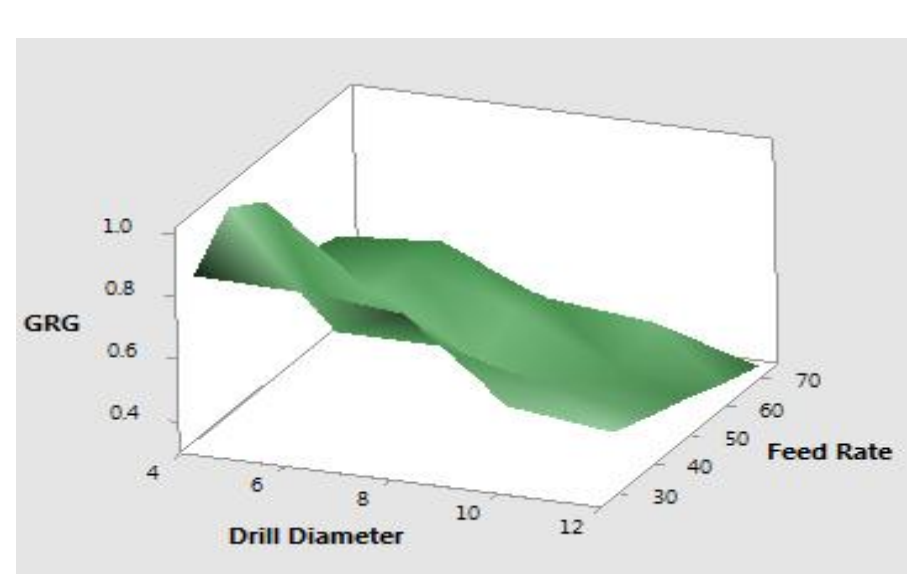




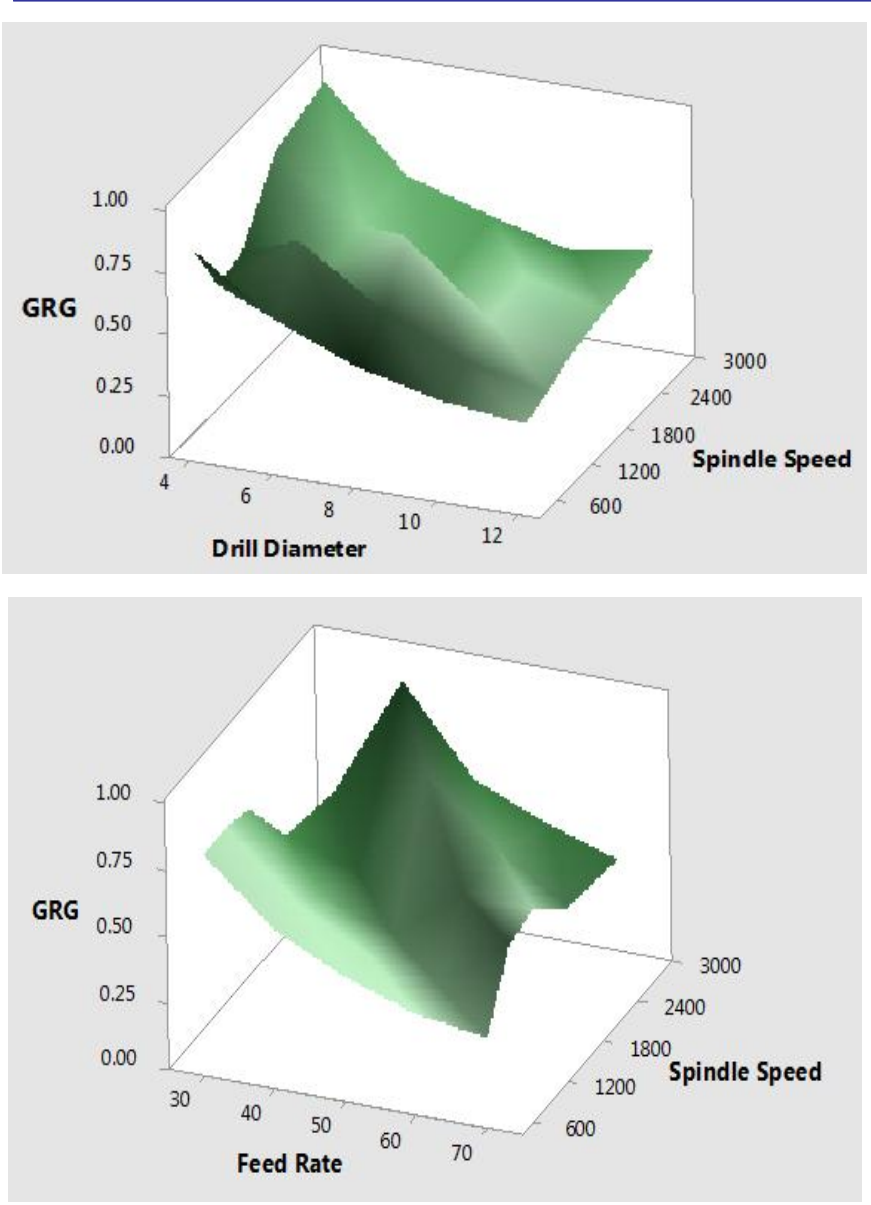

Figure 6. (a) 3d response graph for drill diameter and feed rate; (b) 3d response for drill diameter and spindle speed; (c) 3d response graph for spindle speed and feed rate

\section{CONCLUSION}

The study of delamination in the hybrid polymer composite in inlet and the exit of the drilled holes are carried out at different trials. The spindle speed, feed rate, and drill diameter are the input parameters considered for analysis and from the outcome of the result, the following conclusions are drawn:

1. The drill diameter has the maximum effect on the delamination at the both the ends during drilling of hybrid GFRP composites, followed by feed rate. The spindle speed has a minimal effect of delamination while drilling of hybrid GFRP composites.

2. Taguchi's L25 orthogonal array with Grey relational analysis technique, is a well-suited for determining the optimal solution in drilling of hybrid GFRP composites within the levels analyzed.

3. The multiple responses are converted into a single response characteristic using grey relational technique which simplifies the optimization process.

4. The total number of levels and parameters can be increased to achieve more accurate result.

\section{ACKNOWLEDGMENT}

The authors would like to thank the Karunya university, Tanjore for allowing the scholar to conduct machining test in their laboratory. The authors would also express their gratitude towards Mr. Vinoth, Assistant Professor, Rajalakshmi Engineering College for his support to make measurement of delamination in the drilled holes using machine vision system available in their laboratory.

\section{REFERENCES}

[1] G. Chawla Krishnan, Composite materials science and engineering. New York: Springer;2001

[2] S. Arul, L.Vijayaraghavan, S.K. Malhotra and R. Krishnamurthy, "The effect of vibratory drilling on hole quality in polymeric composites", International Journal of Machine Tools and Manufacture 2006; 46: 250-259.

[3] G. Lubin, Handbook of composites, Van Nostrand Reinhold: New York, 1982.

[4] U.A.Khashaba, "Delamination in the drilling GFR-thermoset composites", Composite structures, 63, 313-332.

[5] N.S.Mohan, S.M.Kulkarni, "Delamination analysis in drilling process of glass fiber reinforced plastic (GFRP) composite materials", Journal of Materials Processing Technology 2007, 186, 265-271.

[6] B.Latha, V.S.Senthilkumar, "Fuzzy rule based modeling of drilling parameters for delamination in drilling GFRP composites", Journalof reinforced plastic and composites 2009, 36,19-27.

[7] P.Ross, Taguchi techniques for quality engineering loss function, orthogonal experiments, parameter and tolerance design, Mcgraw-Hill, NewYork 1998.

[8] J.P.Davim, P.Reis, C.C.Antonio, "Experimental study of drilling glass fiber reinforced plastics (GFRP) manufactured by hand lay up", Composite science and technology 2004, 64; 289-297.

[9] K.Palanikumar, S.Prakash, K.Shanmugam, "Evaluation of delamination in drilling GFRP composite", Mater Manuf Process 2008; 8:858-64.

[10] K.PalaniKumar, B.Latha, V.S.Senthilkumar, Paulo Davim , "Analysis on drilling of glass fiber - reinforced polymer (GFRP) composite using grey relational analysis", Materials and manufacturing Processes 2012; 27: 297-305.

[11] J.Deng, "Introduction to grey theory", Journal of grey systems 1989 , 1(1), 1-24.

[12] N.Tosun, "Determination of optimum parameters for multi performance characteristics in drilling by using grey relational analysis", International journal of advanced manufacturing technology 2006,28 450-455.

[13] Y.Kuo, T.Yang, G.W.Huang, "The use of a grey based Taguchi method for optimizing multi-response stimulation problems", Engineering Optimization 2008, 23 (1), 51-58

[14] H.P.Sung, A.Jiju, Robust Design for Quality Engineering and Six Sigma; World Scientific: Singapore, 2008.

[15] K.Palanikumar, "Application of Taguchi and response surface methodologies for surface roughness in machining glass fiber reinforced plastics by PCD tooling", International Journal of Advanced Manufacturing Technology 2008, 36, 19-27.

[16] C.P.Fung, "Manufacturing process optimization for wear property of fiber-reinforced polybutylene terephthalate composites with Grey relational analysis", Wear 2003, 254, 298-306.

[17] Y.F.Hsiao, Y.S.Tarng, W.J.Huang, "Optimization of plasma arc welding parameters by using the Taguchi method with the Grey relational analysis", Materials and Manufacturing Processes 2008, 23 (1), 51-58.

[18] K.Palanikumar, L.Karunamoorthy, R.Karthikeyan, "Multiple performance optimization of machining parameters on the machining of GFRP composites using carbide (K10) tool", Materials and Manufacturing Processes 2006, 21, 846-852.

[19] G.Santhanakrishnan, " Investigations on machining of FRP composites and their tribological behaviour", Ph.D. thesis, IIT Madras, India, 1990.

[20] C.C.Tsao, "Experimental study of drilling composite materials with step-core drill", Materials and Design 2008, 29, 1740-1744. 